\title{
Interpenetrated Chitosan-Poly(Acrylic Acid-Co-Acrylamide) Hydrogels. Synthesis, Characterization and Sustained Protein Release Studies
}

\author{
Michel Bocourt Povea ${ }^{1}$, Waldo Argüelles Monal ${ }^{2}$, Juan Valerio Cauich Rodríguez ${ }^{3}$, \\ Alejando May Pat ${ }^{3}$, Nancy Badas Rivero ${ }^{1}$, Carlos Peniche Covas ${ }^{1}$ \\ ${ }^{1}$ Department of Macromolecular Chemistry, University of Havana, Havana, Cuba; ${ }^{2}$ Center for Food and Development Research, Unit \\ Guaymas, Sonora, México; ${ }^{3}$ Scientific Research Centre of Yucatan, Mérida, México. \\ Email: bocourt@biomat.uh.cu
}

Received March $1^{\text {st }}, 2011$; revised April 16 ${ }^{\text {th }}, 2011$; accepted May $5^{\text {th }}, 2011$.

\begin{abstract}
Interpenetrated polymer networks of chitosan (CHI), polyacrylic acid (PAA) and polyacrylamide (PAM) were prepared by free radical polymerization. These hydrogels were either washed with double distilled water (CHI/PAA/PAM) A or hydrolyzed with $1 M$ sodium hydroxide $(\mathrm{NaOH}),(\mathrm{CHI} / \mathrm{PAA} / \mathrm{PAM}) \mathrm{S}$. Both types of hydrogels were characterized by infrared spectroscopy, microstructural techniques and compressive mechanical testing. Finally, hydrogels were loaded with bovine serum albumin (BSA) and release followed at different pHs. Infrared spectra analysis showed correspondence between hydrogels and monomer feed compositions. Hydrolyzed hydrogels, had increased water content and $\mathrm{pH}$ swelling dependence. Compression modulus of swelled hydrolyzed hydrogels decreased with increasing equilibrium water content. Higher BSA loadings were achieved on hydrolyzed hydrogels due to their high water content and porosity. Protein release from hydrogels was low ( $\leq 20 \%$ after 10 hours) at $\mathrm{pH} 1.2$, but sustained release was observed at $\mathrm{pH}$ 6.8 and 7.4. The integrity of the protein released at 6.8 and 7.4 by hydrolyzed hydrogels was unaffected. The hydrogles showed no cytotoxic effects on human skin dermal fibroblasts as determined by MTT assay except for two compositions of (CHI/PAA/PAM) A samples, which after seven days presented a viability lower than $80 \%$ respect to the control.
\end{abstract}

Keywords: Hydrogels, Controlled Release, Protein, Polyacrylamide, Interpenetrated Polymer

\section{Introduction}

Hydrogels are three dimensional hydrophilic polymer networks that swell, but do not dissolve, when brought into contact with water [1]. Hydrogels have been actively studied, particularly those experiencing reversible volume changes in response to external stimulus, such as $\mathrm{pH}$, temperature and ionic concentration. These "smart" hydrogels have found applications in biomedicine and biotechnology [2] including soft contact lenses [3], immobilization of enzymes and proteins [4], antibodies and antigens [5] and matrices for drug delivery systems [6,7]. The ability of these hydrogels to respond to their environment increase drug loading and provide protection from environmental conditions such as those found in the gastrointestinal tract [8]. In this regard, stimuli responsive hydrogels can be useful for the design of site-specific drug delivery devices; for instance, colon-specific drug delivery systems. Another important advantage of these hydrogels is that the active ingredient remains on the organ or tissue for longer times than conventional ones [9].

Intelligent hydrogels have also been prepared from interpenetrated polymer networks (IPNs), and it has been found that they combine high swelling capacity with increased mechanical properties $[10,11]$. Superabsorbent hydrogels of poly(acrylamide-co-acrylic acid) characterized mainly by fast swelling and $\mathrm{pH}$ swelling dependence, ionic strength and composition have been prepared by a number of authors [12-14]. These materials have been proposed for different applications, such as waste water purification from textile industry [15], for the environmental analysis of $\mathrm{Cu}$ and $\mathrm{Cd}[16]$ and as mechanical 
transducers [17].

A great variety of systems have been prepared by grafting synthetic polymers onto polysaccharides. Of particular interest are those based on the graft polymerization of monomers such as acryl amide [18], acrylic acid [19], $\mathrm{N}$-isopropylacrylamide [20] and $\mathrm{N}$-vinylpyrrolidone [21] onto chitosan. Chitosan, $(1,4)-[2$-amino-2-deoxy- $\beta$-Dglucan] is a deacetylated derivate of chitin, a natural occurring polymer. It is widely studied in pharmaceutical and biomedical fields because of its biodegradability, biocompatibility, non toxicity and interesting structural properties [22]. The functional amino and hydroxyl groups in chitosan allow the preparation of chitosan derivatives with improved properties under relatively mild conditions [23]. Mahdavinia et al. synthesized poly (acrylic acid-co-acrylamide) grafted chitosan, and studied the effect of the buffer solution, ionic strength and cross-linker concentration on the swelling properties of these systems. They observed that water uptake increased with increasing the acrylic acid concentration in the monomer feed. However after hydrolysis with $1 \mathrm{~N} \mathrm{NaOH}$ at $100^{\circ} \mathrm{C}$ for $60 \mathrm{~min}$ the samples with high acrylamide ratio exhibited increased swelling [24]. However, in this study no use was made of microstructural techniques (EDX, SEM) for characterizing the hydrogels prepared and there was no report on their mechanical properties, biocompatibility and their potential as matrices for drug or protein release.

In the present work we prepare chitosan-poly(acrylic acid-co-acrylamide) IPNs by the free radical co-polymerization of acrylamide and acrylic acid in the presence of chitosan and methylenebisacrylamide as a cross-linker. Chitosan concentration in the feed was kept constant and low in all preparations so as to produce hydrogels with increased $\mathrm{pH}$ sensitivity. The effect of monomer feed composition (either acrylic acid or acrylamide) and alkaline hydrolysis was studied not only in terms on morphology and water uptake but also in terms of their compressive properties. Hydrogel cytotoxicity was assessed by determining viability of cells by the MTT test. Bovine Serum Albumin (BSA) was used as model protein to study their drug release properties. Finally, the effect of $\mathrm{pH}$ on protein release kinetics was also studied.

\section{Experimental}

\subsection{Materials}

Chitosan (CHI; D.D. $=90 \%$ determined by potentiometry, $\mathrm{M}_{\mathrm{v}}=9.3 \times 10^{4}$ ) was purchased from Primex (Iceland). Acrylic acid (AA, Aldrich, Milwaukee, WI) was distilled under reduced pressure before use. Acrylamide (AM; Fluka, Buchs, Switzerland), Ammonium persulfate (APS;
Fluka, Buchs, Switzerland), N,N-methylenebisacrylamide (MBA; Sigma Chemical Co., St. Louis, USA,), N,N,N,N tetramethylenediamine (TEMED; Fluka, Buchs, Switzerland) and bovine serum albumin (BSA; Sigma-Aldrich, Zwijndrecht, Netherlands), $\mathrm{Mw}=6.5000 \times 10^{4}$ ) were used as supplied. All other reagents were of analytical grade and used as received. Double distilled water was used through this work.

\subsection{Methods}

\subsubsection{Preparation of (CHI/PAA/PAM) Hydrogel}

Hydrogels were prepared by free radical polymerization of $\mathrm{AM}$ and $\mathrm{AA}$ in presence of the CHI. A determined mass of AM and AA, together with MBA $\left(3.3 \times 10^{-2} \mathrm{~mol} / \mathrm{L}\right)$, APS $\left(1.2 \times 10^{-3} \mathrm{~mol} / \mathrm{L}\right)$ and TEMED in a 1:1 molar ratio with APS, were added to a $1 \%$ chitosan solution in $1 \%$ acetic acid and stirred for 10 minutes at room temperature. The solution was placed in a glass tube, degassed and sealed in vacuum. Finally the glass tube was placed in a water bath at $50^{\circ} \mathrm{C}$ for $24 \mathrm{~h}$. These hydrogels will be referred to as M1-M6 and their composition is listed in Table 1.

The hydrogels obtained in long cylindrical shapes were sliced into discs of $2 \mathrm{~cm}$ diameter $2 \mathrm{~mm}$ thick. Some hydrogels were washed in double distilled water for approximately 2 weeks to remove unreacted monomer and are named (CHI/PAA/PAM)A and others were hydrolysed with $1 \mathrm{~mol} / \mathrm{L}$ sodium hydroxide solution, during 3 hours and washed with double distilled water until $\mathrm{pH} 7$ was reached. These are identified as (CHI/ PAA/PAM)S. The discs were dried to constant weight at $40^{\circ} \mathrm{C}$ in a vacuum oven.

\subsubsection{FTIR Analysis}

FTIR spectra were obtained with $\mathrm{KBr}$ discs and recorded in the spectral range from 4000 to $400 \mathrm{~cm}^{-1}$ by using a Nicolet model Protege, 460 spectrometer (Nicolet In-

Table 1. Relative composition of the reaction mixtures for the preparation of (CHI/PAA/PAM) systems.

\begin{tabular}{ccccc}
\hline SAMPLES & CHI (g) & AA (g) & AM (g) & $\begin{array}{c}\text { Monomer feed ratio } \\
\text { CHI/AA/AM } \\
(\mathrm{wt} \%)\end{array}$ \\
\hline M1 & 0.08 & 0.00 & 0.72 & $10 / 0 / 90$ \\
M2 & 0.08 & 0.08 & 0.64 & $10 / 10 / 80$ \\
M3 & 0.08 & 0.16 & 0.56 & $10 / 20 / 70$ \\
M4 & 0.08 & 0.36 & 0.36 & $10 / 45 / 45$ \\
M5 & 0.08 & 0.56 & 0.16 & $10 / 70 / 20$ \\
M6 & 0.08 & 0.72 & 0.00 & $10 / 90 / 0$ \\
\hline
\end{tabular}


strument Corp., Madison, WI). Spectra were obtained with a resolution of $2 \mathrm{~cm}^{-1}$ and were averaged over 100 scans.

\subsubsection{Swelling Studies}

The discs were cut into fragments of about $30 \mathrm{mg}$ and weighed accurately. These fragments were placed into flasks with $10 \mathrm{~mL}$ solution of a given $\mathrm{pH}$ and kept in a thermostated bath at $37^{\circ} \mathrm{C}$. Solutions with $\mathrm{pH} 1.2$ (simulated gastric fluid), $\mathrm{pH} 7.4$ (phosphate buffered saline), and $\mathrm{pH} 6.8$ (double distilled water) were prepared. The water uptake, $\mathrm{W}$, was calculated by measuring the weight gain of the sample at different times after carefully wiping the surface with a filter paper. It was reported as

$$
W=\frac{W_{t}-W_{0}}{W_{0}}
$$

where $W_{0}$ is the weight of the dry sample and $W_{t}$ is that of the sample at time $t$.

\subsubsection{Scanning Electron Microscopy (SEM)}

The morphology of the hydrogels was determined using a scanning electron microscope (SEM-JEOL JSM$6360 \mathrm{LV}$, Japan). Small pieces of swelled gels were freeze-dried to avoid the collapse of porous structure. Then they were cut with a knife to expose the inner surface. Samples were placed on an aluminum mount, sputtered with gold palladium, and then scanned at an accelerating voltage of $15 \mathrm{kV}$.

\subsubsection{Mechanical Properties}

For the determination of compressive properties, fully swollen hydrogels were cut into cylindrical species of 6 $\mathrm{mm}$ diameter and $12 \mathrm{~mm}$ length measured with a Mitutoyo digital caliper. Hydrogels were confined in a cylindrical metal frame and compressed at $0.5 \mathrm{~mm} / \mathrm{min}$, using a Minimat testing machine with a $10 \mathrm{~N}$ load cell. The stress $(\sigma)$ and strain $(\varepsilon)$ were obtained according to Equations (2) and (3).

$$
\begin{gathered}
\sigma=\frac{P}{A} \\
\varepsilon=\frac{l_{F}}{l_{0}}
\end{gathered}
$$

where $P$ represents the compression force, $A$ the area of the cylinder and $l_{0}$ and $l_{F}$ are the initial and final length, respectively. From the initial portion of the stress-strain curve, the modulus was obtained and the values reported as the mean $\pm \mathrm{SD}$ of six determinations.

\subsubsection{Elemental Analysis}

Elemental analysis $(\mathrm{C}, \mathrm{N}, \mathrm{O}$ and $\mathrm{Na}$ ) was conducted with an INCA 7582 Elemental Microanalyzer (Oxford Instruments, UK) coupled to the Jeol JSM-6360LV SEM.

\subsubsection{BSA Release Studies}

\subsubsection{BSA Loading}

Dried sample discs weighing $30 \mathrm{mg}$ were placed in vials containing $10 \mathrm{~mL}$ of aqueous solutions of BSA $(1.0 \mathrm{mg} /$ $\mathrm{mL}$ ). Then, vials were placed in a temperature-regulated incubator at $4^{\circ} \mathrm{C}$. After 7 days, hydrogels were separated from the solutions and freeze-dried. The concentration of the supernatant solutions were analyzed with the modified Coomassie Blue protein assay (Biorad) using UV spectroscopy at 595 to determine the amount of BSA loaded in each hydrogel disc [25]. The BSA load in hydrogels was determined from the difference in the solutions concentrations before and after incubation. All experiments were performed in triplicate.

\subsubsection{In Vitro Protein Release Study}

Release of BSA was carried out as established by the USP XXIV Standard. Three different release media were tested: simulated gastric fluid (SGF), consisting of $\mathrm{NaCl}$ $(2.0 \mathrm{~g}), \mathrm{HCl}(7 \mathrm{~mL})$ and $\mathrm{pH}$ adjusted to $1.2 \pm 0.5$; simulated intestinal fluid (SIF), consisting of $\mathrm{KH}_{2} \mathrm{PO}_{4}(6.8 \mathrm{~g})$, $0.2 \mathrm{~N} \mathrm{NaOH}(77 \mathrm{~mL})$, and $\mathrm{pH}$ adjusted to $6.8 \pm 0.1$. Phosphate buffered saline (PBS) 7.4 was prepared with deionized water. For release studies the BSA-loaded hydrogel discs were suspended in $10 \mathrm{~mL}$ of these solutions at $37^{\circ} \mathrm{C}$ in a ZHICHENG ZHWX-200B Incubator with reciprocating motion $(100 \mathrm{rpm})$. At predetermined time intervals, $200 \mu \mathrm{l}$ aliquots were removed and simultaneously replenished by $200 \mu \mathrm{l}$ of fresh solutions to maintain sink conditions. Protein content of each sample was analyzed with the modified Coomassie Blue protein assay (Biorad) using UV spectroscopy at $595 \mathrm{~nm}$. A calibration curve was generated at each time interval using a non-loaded gel in order to correct for the intrinsic absorbance of the polymer. All experiments were performed in triplicate.

\subsubsection{Analysis of Released Proteins by Gel Electrophoresis (SDS-PAGE)}

The structural integrity of BSA released from CHI/PAA/ PAM) hydrogels was analyzed by SDS-PAGE in 10\% acrylamide gels according to Laemli [26] using a MiniProtean II Cell (Bio-Rad Laboratories Hercules, CA, USA). BSA solutions were directly loaded into the test wells with a micropipette, and the electrophoresis was performed at $100 \mathrm{~V}$. The gel was stained with $0.1 \%$ $\mathrm{AgNO}_{3}$ to visualize protein bands. The study was conducted according to the manufacturer's protocol. The gel pictures were taken with a scanner after wiping off all the water from the gel membrane. 


\subsection{Cytotoxicity Test}

\subsubsection{In Vitro Cell Culture for Biocompatibility Experiment}

Sterile hydrogel pieces M1-M6 (CHI/PAA/PAM)A and M1-M6 (CHI/PAA/PAM)S of uniform weight $(50 \mathrm{mg}$ each) were used for biocompatibility experiments. The negative control was tissue culture plastic, Thermanox (TMX), in discs of $13 \mathrm{~mm}$ diameter (Nunc) and the positive control (toxic agent) was Triton-1\% (Merck). Experiments were carried out using human skin dermal fibroblasts (Pharmakine DPK-SKDF-H). Cells were cultured at $37^{\circ} \mathrm{C}$ and $5 \% \mathrm{CO}_{2}$. The culture medium was Dulbecco's modified Eagle's medium (DMEM), modified with HEPES (Sigma), rich in glucose and supplemented with $10 \%$ (v/v) fetal bovine serum (FBS; Gibco), $200 \mathrm{mM}$ glutamine (Sigma), 1\% of penicillin-streptomycin solution (10000 Units $/ \mathrm{mL}$ penicillin and $10 \mathrm{mg} / \mathrm{mL}$ streptomycin, Sigma). The culture medium was changed at selected time intervals with care to cause little disturbance to culture conditions.

\subsubsection{MTT Assay}

TMX, M1-M6 (CHI/PAA/PAM)A and M1-M6 (CHI/ $\mathrm{PAA} / \mathrm{PAM}$ )S discs were set up in $5 \mathrm{~mL}$ of DMEM. They were placed on a roller mixer at $37^{\circ} \mathrm{C}$ and the medium was removed at different time periods ( $8 \mathrm{~h}, 1,4,7$ days) [27] and replaced with other $5 \mathrm{~mL}$ of fresh medium. All the extracts were obtained under sterile conditions. Fibroblasts cells were seeded at a density of $10^{5}$ cells $/ \mathrm{mL}$ in complete medium in a sterile 96-well culture plate and incubated to confluence. Then, the medium was replaced with the corresponding eluted extract and incubated at $37^{\circ} \mathrm{C}$ for $24 \mathrm{~h}$. A solution of MTT was prepared in warm PBS $(0.5 \mathrm{mg} / \mathrm{mL}$; Sigma $)$ and the plates were incubated at $37^{\circ} \mathrm{C}$ for $4 \mathrm{~h}$. Excess medium and MTT were removed and $100 \mu$ ld dimethylsulphoxide (DMSO; Sharlau) was added to all wells in order to dissolve the MTT taken up by the cells. This was mixed for $10 \mathrm{~min}$ and the absorbance was measured with a Biotek SYNERGY spectrophotometer using a test wave length of $570 \mathrm{~nm}$ and a reference wave length of $630 \mathrm{~nm}$. From the values of relative cell viability a statistical analysis was carried out using Student $t$ test in order to detect significant differences between the distribution of measured values for the negative control and those obtained for the experimental groups studied.

\section{Results and Discussion}

\subsection{Synthesis and Spectral Characterization}

The free radical polymerization of AA and AM in the presence of chitosan results in a hydrogel in which chi- tosan chains become grafted with the copolymer [19,24]. The use of the difunctional monomer MBA in the reacting mixture promotes the formation of a tridimensional interpenetrated polymer network reinforcing the mechanical properties of the hydrogel as well as restraining its swelling capacity [28]. During the alkaline treatment, amide groups are hydrolyzed into carboxylate ions. The FTIR spectra of CHI, AM, AA, (CHI/PAA/PAM)A and (CHI/PAA/PAM)S for composition corresponding to M5 are shown in Figure 1(A).

The spectra of hydrogels at other compositions were qualitatively similar to that of M5 and are not shown. Chitosan spectrum exhibited the distinctive absorption bands at $1658 \mathrm{~cm}^{-1}$ (Amide I), $1595 \mathrm{~cm}^{-1}$ (-NH $\mathrm{NH}_{2}$ bending) and $1314 \mathrm{~cm}^{-1}$ (Amide III). The absorption bands at $1154 \mathrm{~cm}^{-1}$ (anti-symmetric stretching of the $\mathrm{C}-\mathrm{O}-\mathrm{C}$ bridge), 1082 and $1032 \mathrm{~cm}^{-1}$ (skeletal vibrations involving the $\mathrm{C}-\mathrm{O}$ stretching) are characteristic of its saccharide structure [29].

The IR spectrum of PAA exhibits the characteristic absorption band at $1728 \mathrm{~cm}^{-1}$ due to the $\mathrm{C}=\mathrm{O}$ stretching vibration of the carboxylic groups. The intense band at $1670 \mathrm{~cm}^{-1}$ in the spectrum of PAM corresponds to the $\mathrm{C}=\mathrm{O}$ stretching vibration (Amide I). The main absorption bands of the CHI, AM, AA infrared spectra, appeared also in (CHI/PAA/PAM)A and (CHI/PAA/PAM)S spectra. The bands at $1558 \mathrm{~cm}^{-1}$ (asymmetric $\mathrm{COO}^{-}$stretching) and $1406 \mathrm{~cm}^{-1}$ (symmetric $\mathrm{COO}^{-}$stretching) present in the (CHI/PAA/PAM) S spectrum result from the alkaline hydrolysis of the amide groups of AM into carboxylate ions.

Since the strong absorption band at $1082 \mathrm{~cm}^{-1}$ in the chitosan spectrum is absent in the spectrum of PAM, the ratio of the intensity of the absorption band at $1630 \mathrm{~cm}^{-1}$ $\left(\mathrm{A}_{1630}\right)$ to the intensity of the absorption band at 1082 $\mathrm{cm}^{-1}\left(\mathrm{~A}_{1082}\right)$ was used as indicative of the composition of the sample. As it can be seen in Figure 1(B) the absorption bands ratio $A_{1670} / A_{1082}$ is very sensitive to the $A M$ composition of the systems i.e. it decreased when the concentration of AA increased in the reaction mixture. This trend indicates that the proportion of AA in the hydrogels increased from M1 to M6, as expected from the monomer feed composition. Furthermore, the values of the ratio $\mathrm{A}_{1670} / \mathrm{A}_{1082}$ for $(\mathrm{CHI} / \mathrm{PAA} / \mathrm{PAM}) \mathrm{S}$ hydrogels were smaller than those of the corresponding (CHI/PAA/ PAM)A samples indicating that hydrolysis of the amide groups on PAM to carboxylate ions was effectively achieved by the treatment with $\mathrm{NaOH}$.

EDX analysis of hydrogels corroborated the IR spectroscopy results. Figures 2(a) and (b) show the EDX of the sample M4 (CHI/PAA/PAM)A and M4 (CHI/PAA/ $\mathrm{PAM}) \mathrm{S}$, respectively, which are representative of the 


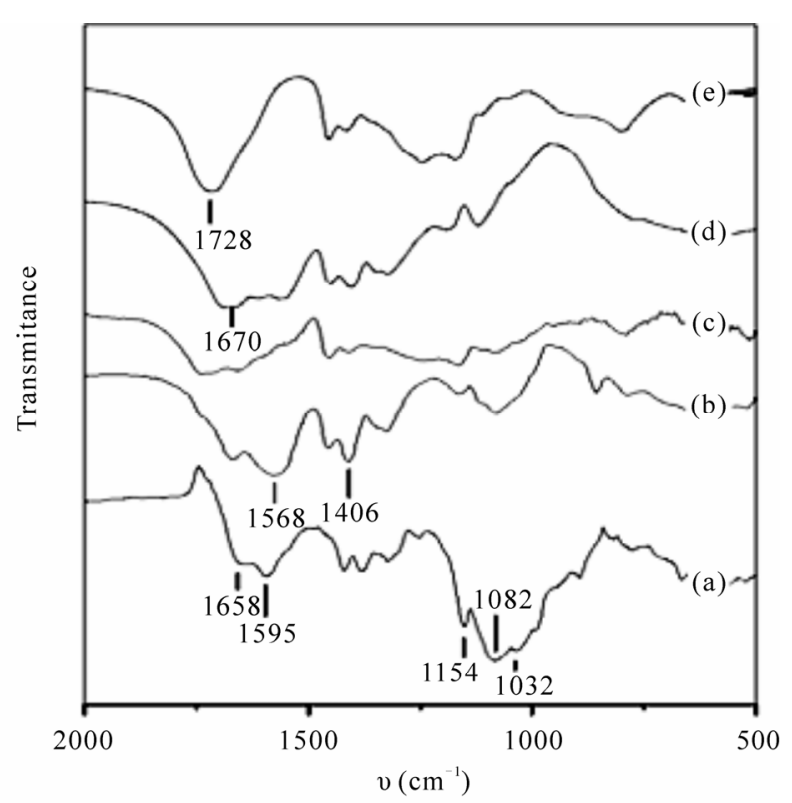

(A)

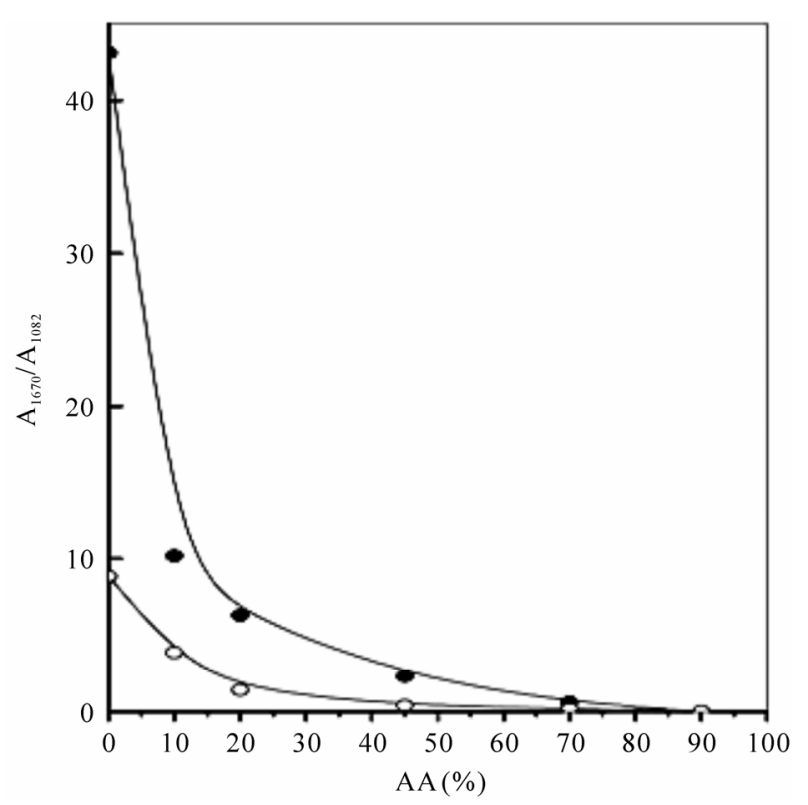

(B)

Figure 1. (A): FTIR spectra of (a), CHI; (b), M5(CHI/PAA/ PAM)S; (c) M5(CHI/PAA/PAM)A; (d) PAM and (e) PAA. (B): Absorption bands ratio $A_{1670} / A_{1082}$ of $(\bullet)$, (CHI/PAA/ PAM)A and ( $\odot),($ CHI/PAA/PAM)S hydrogels as function of the initial acrylic acid composition in the polymerization mixture.

corresponding series.

The peak at $1.05 \mathrm{keV}$ assigned to the presence of sodium (Na) was observed in Figure 2(b) and attributed to the formation of sodium carboxylate salts resulting from the basic hydrolysis of acrylamide moieties.

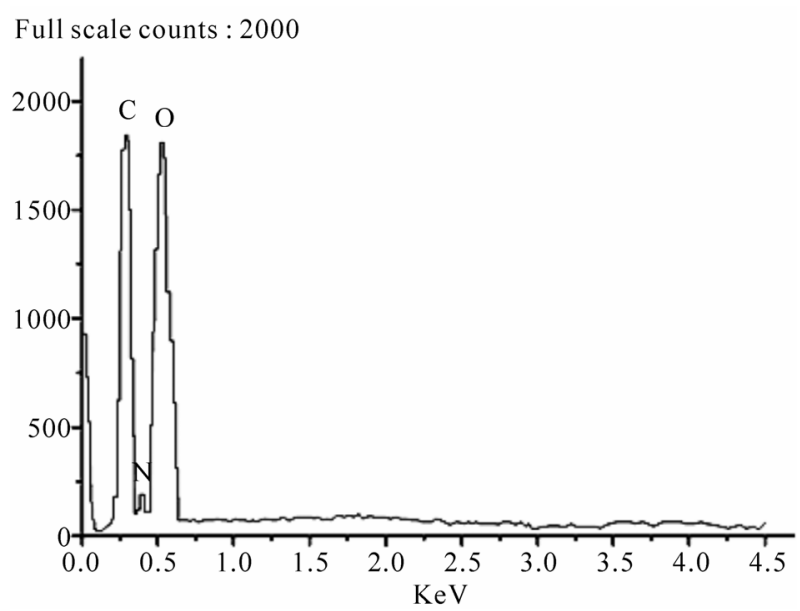

(a)

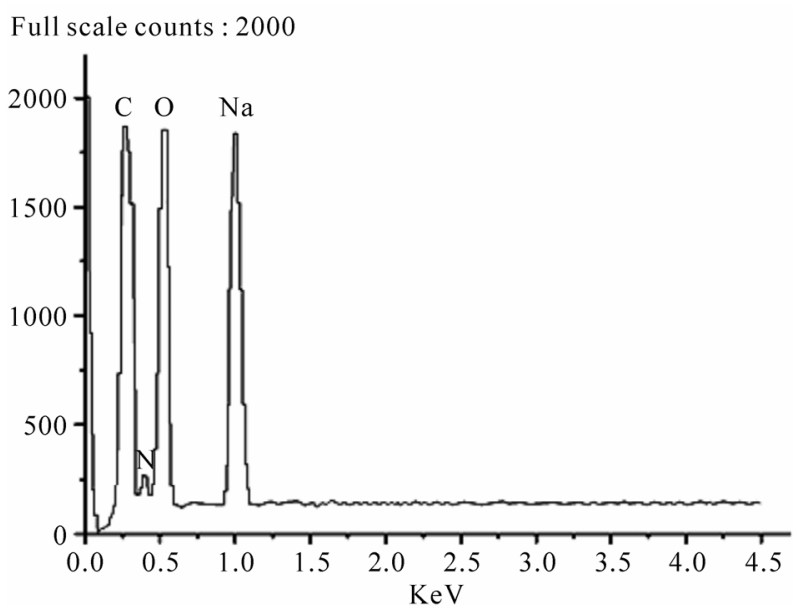

(b)

Figure 2. EDX analysis of hydrogels (a): M4(CHI/PAA/ PAM)A, (b): M4(CHI/PAA/PAM)S.

\subsection{Swelling of Hydrogels}

Swelling kinetics of (CHI/PAA/PAM)A and (CHI/PAA/ PAM)S hydrogels in water has been reported before Bocourt et al. [30]. In general, swelling was fast in both cases, although the rate of water uptake in hydrolyzed samples was always higher than the corresponding non-hydrolyzed ones. The process followed a second order kinetics with respect to the remnant swelling. This behavior is typical of processes in which solvent diffusion is controlled by the relaxation of chains [31]. Water swelling at equilibrium of (CHI/PAA/PAM)A and (CHI/ PAA/PAM)S hydrogels prepared at different monomer feed ratios are shown in Figure 3.

As expected, swelling is strongly dependent on composition, since the hydrophilic character of the functional groups provided by the structural units in the hydrogels is 


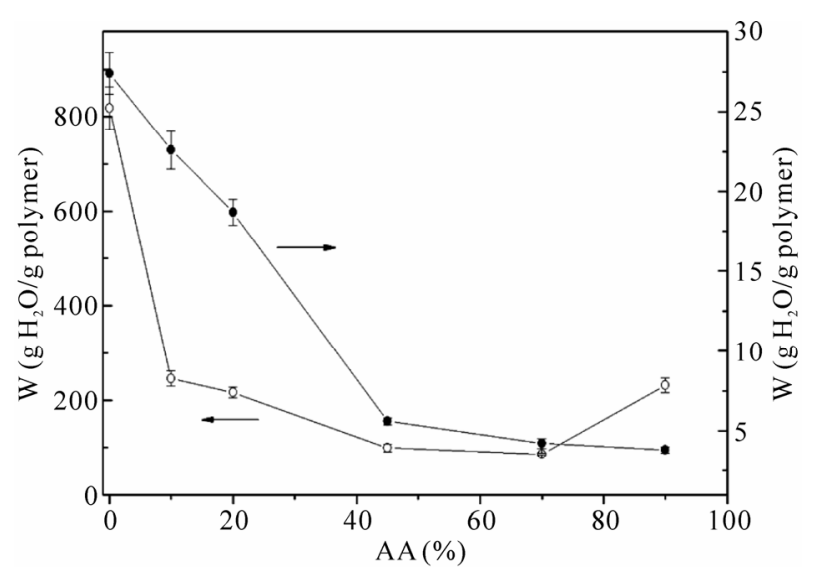

Figure 3. Equilibrium (ultimate) swelling in water of $(\bullet)$, (CHI/PAA/PAM)A and (०), CHI/PAA/PAM)S hydrogels as function of the initial acrylic acid composition in the polymerization mixture.

not the same, but varied in the order: $-\mathrm{COO}^{-}>-\mathrm{COOH}>$ $-\mathrm{CONH}_{2}>-\mathrm{OH}$. In addition, interactions between functional units can affect swelling. For instance, swelling of (CHI/PAA/PAM)A hydrogels decrease as the AM/AA ratio decreases, due to the formation of hydrogen bonding between carboxylic groups in PAA and amide groups in AM. These hydrogen bonds introduce additional cross-links to the hydrogel network decreasing its swelling capacity. Complexation of PAA with PAM and poly(AA-co-AM) has been reported by K. Sivadasan et al. [32] using pyrene labeled polymers.

In the absence of AM (sample M6) there is a further decrease in swelling which should be attributed to the formation of interpolyelectrolyte salt bonds between the amino groups of chitosan and the carboxylic groups of AA moieties. This will introduce additional cross-links to the network, with the consequent decrease in swelling. (CHI/PAA/PAM)S hydrogels have higher swelling capacity than the (CHI/PAA/PAM)A hydrogels (Figure 3) as a consequence of the formation of carboxylate ions resulting from the basic hydrolysis of amide groups of acrylamide units. These negatively charged carboxylate ions are highly solvated and the repulsion between them provoke the expansion of the hydrogel network absorbing more water than the neutral amide groups. Although both factors increase swelling, this effect is more noticeable on M1 samples whose composition is the richest in PAM. As the AM/AA ratio decreases from M2 to M5 less water is absorbed, although swelling was always higher than that of the corresponding (CHI/PAA/PAM)A hydrogels. A point to note is that sample M6 exhibited a significantly higher swelling compared to samples M4 and M5. Apparently in the latter two there are still some interactions between non-hydrolised AM units and several non-dissociated carboxylic groups of AA. The $\mathrm{pH}$ dependence of the swelling capacity of hydrogels was evaluated at $\mathrm{pH} 1.2$ and $\mathrm{pH} 7.4$ and the results are reported in Table 2.

Swelling of (CHI/PAA/PAM)A hydrogels (samples $\mathrm{M} 2$ to M6) is higher at $\mathrm{pH} 7.4$ than at $\mathrm{pH} 1.2$ due to the dissociation of the carboxylic units of AA above $\mathrm{pH} 4.7$ $\left(\mathrm{pK}_{\mathrm{a}}=4.7\right)$. However, no significant change in swelling with $\mathrm{pH}$ was observed for sample M1, due to the neutral character of acrylamide. At $\mathrm{pH} 1.2$ the free amino groups of chitosan are protonated, but its proportion in M1 is so low that its effect on swelling is negligible. Similar behavior is observed for (CHI/PAA/PAM)S hydrogels (samples M1 to M5). In this case sample M1 also exhibit swelling dependence on $\mathrm{pH}$ since some of its neutral amide groups have been hydrolyzed. On the other hand, swelling of sample M6(CHI/PAA/PAM)S at $\mathrm{pH} 1.2$ and 7.4 do not differ significantly with swelling of sample M6(CHI/PAA/PAM)A since their composition was not altered by the alkaline treatment.

The effect of ionic strength on (CHI/PAA/PAM) hydrogels swelling can be appreciated by comparing the swelling degrees of (CHI/AA/AM)S hydrogels at $\mathrm{pH} 7.4$ (see Table 2) with those achieved in water (see Figure 3).

Table 2. Swelling capacity of (CHI/PAA/PAM)A and (CHI/PAA/PAM)S at different pH.

\begin{tabular}{cccccc}
\hline \multirow{2}{*}{ Samples } & CHI/AA/AM $(w t \%)$ & \multicolumn{2}{c}{$(\mathrm{CHI} / \mathrm{AA} / \mathrm{AM}) \mathrm{A}$} & \multicolumn{2}{c}{$(\mathrm{CHI} / \mathrm{AA} / \mathrm{AM}) \mathrm{S}$} \\
\cline { 3 - 6 } & $10 / 0 / 90$ & $14.0 \pm 0.7$ & $13.2 \pm 0.1$ & $11.5 \pm 0.9$ & $16.3 \pm 0.7$ \\
\hline M1 & $10 / 10 / 80$ & $10.3 \pm 0.3$ & $21.5 \pm 1.3$ & $6.7 \pm 0.7$ & $26.0 \pm 1.6$ \\
M2 & $10 / 20 / 70$ & $6.9 \pm 0.4$ & $23.2 \pm 1.0$ & $4.2 \pm 0.2$ & $27.5 \pm 1.4$ \\
M3 & $10 / 45 / 45$ & $3.9 \pm 0.2$ & $24.6 \pm 1.5$ & $2.4 \pm 0.1$ & $28.1 \pm 1.4$ \\
M4 & $10 / 70 / 20$ & $2.9 \pm 0.1$ & $24.9 \pm 1.7$ & $2.1 \pm 0.1$ & $28.6 \pm 1.9$ \\
M5 & $10 / 90 / 0$ & $1.6 \pm 0.1$ & $29.8 \pm 1.9$ & $1.5 \pm 0.1$ & $32.5 \pm 1.6$ \\
M6 & & & & & \\
\hline
\end{tabular}


This occurs because the ionic strength provided by the phosphate buffered saline $(I=0.2)$ hampers swelling in spite of the higher dissociation degree expected for the carboxylic groups of AA at $\mathrm{pH}$ 7.4. In this case, charge screening of the counterions on the fixed charges of the polymer network, leads to a decrease in the osmotic pressure [33].

\subsection{Morphologic Studies}

Figure 4 shows the SEM pictures of M4(CHI/PAA/ PAM)A and M4(CHI/PAA/PAM)S hydrogels. From these pictures, the higher porosity of the hydrolyzed sample is evident. The same morphologies were observed for hydrogels prepared at other compositions.

This increased porosity allows faster water diffusion through the hydrogel network which in turn is another factor that contributes to the higher rate of water uptake observed in hydrolyzed samples. It is important to mention that even when elimination of water by different means leads to different structures, in this case the same method was used for all hydrogels.

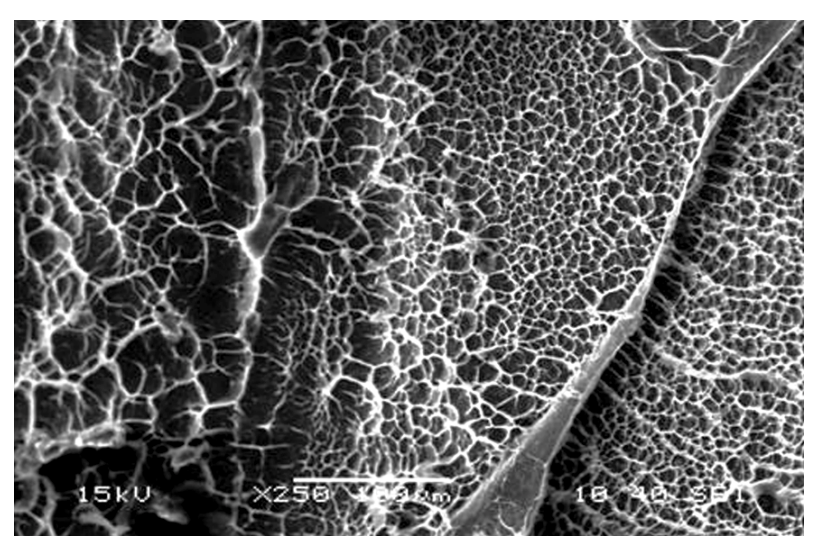

(a)

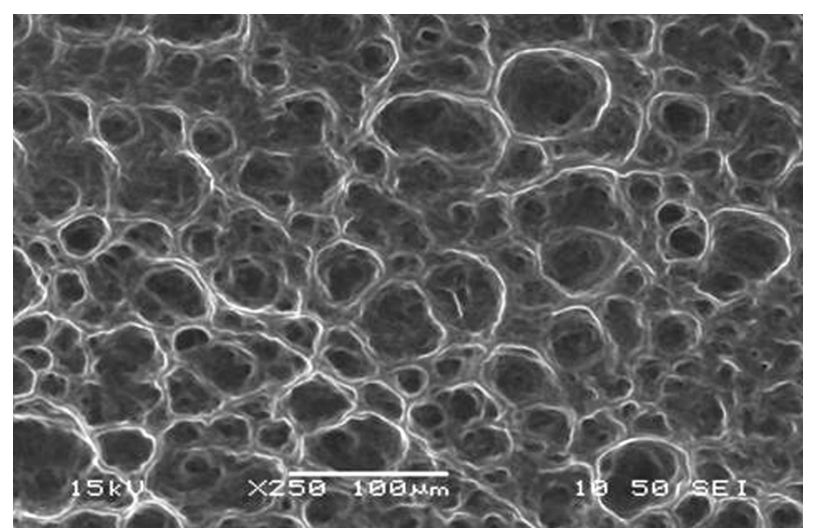

(b)

Figure 4. SEM pictures of M4 hydrogels: (a) M4(CHI/ PAA/PAM)A and (b) (CHI/PAA/PAM)S.

\subsection{Mechanical Properties}

Hydrogels can swell to several hundred times within a few minutes. However, the modulus of hydrogels will decrease when decreasing polymer fraction, as predicted by rubber elasticity theory. Therefore, highly swelled hydrogels are usually mechanically poor and difficult to handle without breaking. This is an obvious limitation for applications requiring mechanical performance like soft tissue replacement and addition to drug release matrices. In relation to this, the preparation of semi-interpenetrated or interpenetrated polymer networks is a suitable procedure to achieve superabsorbent hydrogels with better mechanical properties. The improvement of the mechanical properties of IPN hydrogels is due to an increase in polymer mass as well as inter- and intra-molecular interactions from the incorporation of the second network into the normal hydrogel network. The initial compression modulus of (CHI/PAA/PAM)S systems with different composition at equilibrium swelling are shown in Table 3.

As expected, the compression modulus decreases in the sequence $\mathrm{M} 5>\mathrm{M} 4>\mathrm{M} 3>\mathrm{M} 6>\mathrm{M} 2>\mathrm{M} 1$, i.e. by increasing hydrogel water content. The values of the compression moduli found for (CHI/PAA/PAM)S hydrogels are of the same order of magnitude as those reported by Tang et al. [34] for high mechanical strength (PAA/PAM) IPN hydrogels.

\subsection{BSA Incorporation and in Vitro Protein Release}

Therapeutic protein administration usually faces the need of frequent doses due to the small residence time in blood of the protein. A promising strategy to overcome this drawback is the development of sustained drug release systems based on hydrogel matrices loaded with the therapeutic drug [35].

Loading capacities for BSA of (QUI/PAA/PAM)A and (QUI/PAA/PAM)S are reported in Table 4, together with

Table 3. Compression modulus and swelling capacity in water of (CHI/PAA/PAM)S hydrogels.

\begin{tabular}{ccc}
\hline SAMPLES & $\begin{array}{c}\text { COMPRESSION } \\
\text { MODULUS }(\mathrm{kPa})\end{array}$ & $\begin{array}{c}\text { SWELLING } \\
\left(\mathrm{g} \mathrm{H}_{2} \mathrm{O} / \mathrm{g} \text { polymer }\right)\end{array}$ \\
\hline M1 & $45 \pm 2$ & $819 \pm 45$ \\
M2 & $68 \pm 2$ & $246 \pm 16$ \\
M3 & $84 \pm 3$ & $216 \pm 11$ \\
M4 & $110 \pm 7$ & $99 \pm 8$ \\
M5 & $122 \pm 9$ & $86 \pm 2$ \\
M6 & $76 \pm 4$ & $231 \pm 16$ \\
\hline
\end{tabular}


Table 4. Protein load and swelling of (CHI/PAA/PAM)A and (CHI/PAA/PAM)S hydrogels in $1 \mathrm{mg} / \mathrm{mL}$ BSA solution.

\begin{tabular}{ccccc}
\hline \multirow{2}{*}{ Samples } & \multicolumn{2}{c}{$(\mathrm{CHI} / \mathrm{PAA} / \mathrm{PAM}) \mathrm{A}$} & \multicolumn{2}{c}{$(\mathrm{CHI} / \mathrm{PAA} / \mathrm{PAM}) \mathrm{S}$} \\
\cline { 2 - 5 } & Load $(\mathrm{mg} / \mathrm{g})$ & $\begin{array}{c}\text { Swelling } \\
\left(\mathrm{g} \mathrm{H} \mathrm{H}_{2} \text { /g polymer }\right)\end{array}$ & Load $(\mathrm{mg} / \mathrm{g})$ & $\begin{array}{c}\text { Swelling } \\
\left(\mathrm{g} \mathrm{H} \mathrm{H}_{2} \mathrm{O} / \mathrm{g} \text { polymer }\right)\end{array}$ \\
\hline M1 & 232.2 & 25.7 & 511.3 & 677.8 \\
M2 & 202.2 & 20.8 & 618.3 & 210.7 \\
M3 & 141.9 & 15.3 & 730.4 & 166.5 \\
M4 & 0 & 4.2 & 323.6 & 72.5 \\
M5 & 0 & 3.1 & 200.6 & 63.8 \\
M6 & 0 & 1.9 & 172.7 & 185.6 \\
\hline
\end{tabular}

the water uptake of hydrogels in these experimental conditions. In the case of (QUI/PAA/PAM)A hydrogels only samples M1 to M3 were able to incorporate the protein. Apparently, both low swelling and small pore sizes on samples M4 to M6 did not allow BSA incorporation.

On the other hand, highly swollen (QUI/PAA/PAM)S hydrogels incorporated BSA at all compositions. Higher loadings were achieved for samples with lower AA content (M1 to M3) while samples M4 and M5 which are richer in AA content, exhibited lower swelling. The cause of this should be the higher density of carboxylate groups these samples should posses in the surface, which could hamper BSA adsorption by anionic electrostatic repulsion between the protein and the hydrogel surface. This explains why sample M6 (which is essentially a CHI/PAA hydrogel) having a similar swelling degree as sample M3 exhibits only $24 \%$ its BSA loading capacity. A similar effect was reported by Karadag et al. [36] for BSA adsorption on acrylamide-itaconic acid hydrogels.

BSA release from (CHI/PAA/PAM) hydrogels was studied at three different pHs: pH 1.2 (SGF); pH 6.8, (SIF), and $\mathrm{pH} 7.4$ (PBS). Figure 5 shows the in vitro cumulative release profiles of the BSA loaded (CHI/ PAA/PAM)A hydrogels. At $\mathrm{pH} 1.2$ protein release is favored in AM richer samples (M1 > M2 > M3), since in acid medium the hydrogels containing AA units become more compact due to hydrogen bonding of carboxylic groups of AA with the amide groups of AM units.

However, a considerable amount of BSA remains trapped in the gels at $\mathrm{pH} 1.2$, presumably due to interactions between the protein and the polymer. At $\mathrm{pH} 6.8$ and 7.4 the carboxylic groups of AA are dissociated $(\mathrm{pKa}=$ 4.7), and the consequent expansion of the gels together with the electrostatic repulsive force between the $\left(\mathrm{COO}^{-}\right)$ charged sites of AA and BSA ( $\mathrm{pK}=4.8$ ) favours protein release, reaching 80 per cent at $\mathrm{pH} 6.8$ and almost 100 per cent at $\mathrm{H} \mathrm{7.4.} \mathrm{It} \mathrm{is} \mathrm{worth} \mathrm{pointing} \mathrm{out} \mathrm{that} \mathrm{BSA} \mathrm{re-}$ lease form (CHI/PAA/PAM) hydrogels was relatively fast at $\mathrm{pH} 6.8$ and 7.4 because after 10 hours it reached almost 100 per cent.

On the other hand, BSA release from (QUI/PAA/ PAM)S hydrogels (Figure 6) at pH 1.2 was even lower than that of (CHI/PAA/PAM)A samples (about 20 per cent for all compositions).

This is to be expected since at this $\mathrm{pH}$ they should be more compact due to poorer swelling (see Table 2) than (CHI/PAA/PAM)A hydrogels. At pH 6.8 and 7.4 protein release resulted slower and more composition dependent for (QUI/PAA/PAM)S than for (QUI/PAA/PAM)A hydrogels. BSA release increased with increasing AA content $(\mathrm{M} 1<\mathrm{M} 2<\mathrm{M} 3<\mathrm{M} 4<\mathrm{M} 5<\mathrm{M} 6)$. Best release profiles were obtained at $\mathrm{pH} 7.4$ for samples M4 to M6, which after liberating approximately $20 \%$ of the protein during the first hour exhibited sustained release for the 48 hours of the experiment.

\subsection{BSA Structural Integrity}

The effect of the loading-release process on the integrity of BSA was studied, since it may have affected the protein structure and stability. Possible detrimental effects include protein denaturation, aggregation and hydrolysis. Experiments were carried out on the BSA released from (QUI/PAA/PAM)A and (QUI/PAA/PAM)S hydrogels after 2 days and compared with the original BSA in solution (a BSA standard).

Figure 7 shows the SDS-PAGE results of the released and commercial BSA. Molecular weight markers are shown in lane I. The SDS-PAGE gel banding patterns of the BSA released from the (QUI/PAA/PAM)A hydrogels at $\mathrm{pH} 1.2,6.8$ and 7.4 are shown in lanes II, III and IV respectively. Similarly the protein released from the (QUI/PAA/PAM)S hydrogels at $\mathrm{pH} 1.2,6.7$ and 7.4 appear in lanes V, VI and VII, respectively and the commercial BSA, lane VIII, exhibited clear bands at $66 \mathrm{KDa}$. The presence of bands of lower molecular weight species in lanes II, III and V indicates appreciable modification 

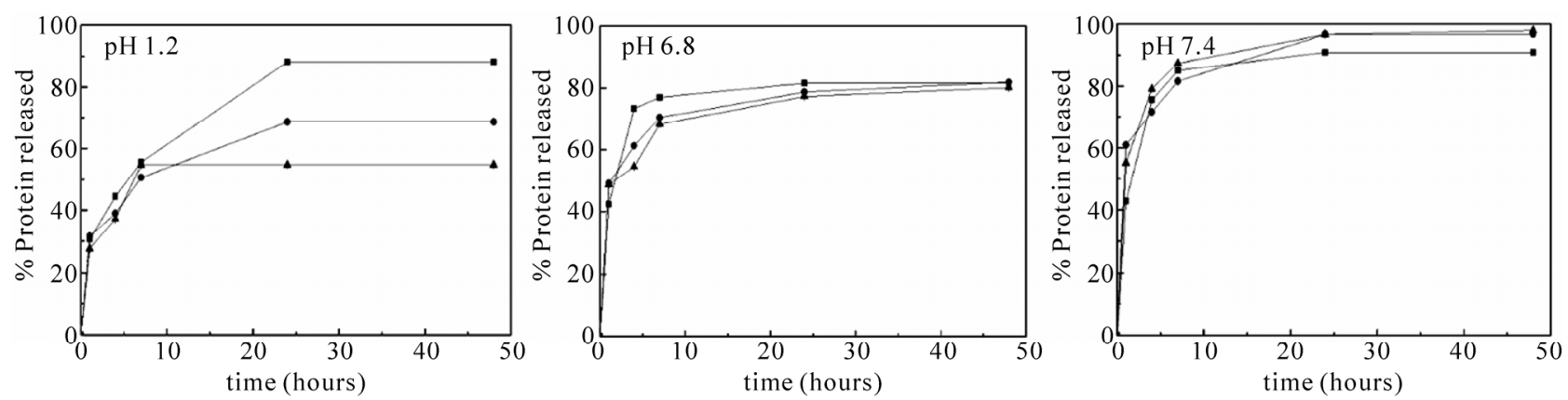

Figure 5. In vitro cumulative release profiles of BSA from (CHI/PAA/PAM)A hydrogels at various pH. (ロ) M1; (•) M2; (A) M3.
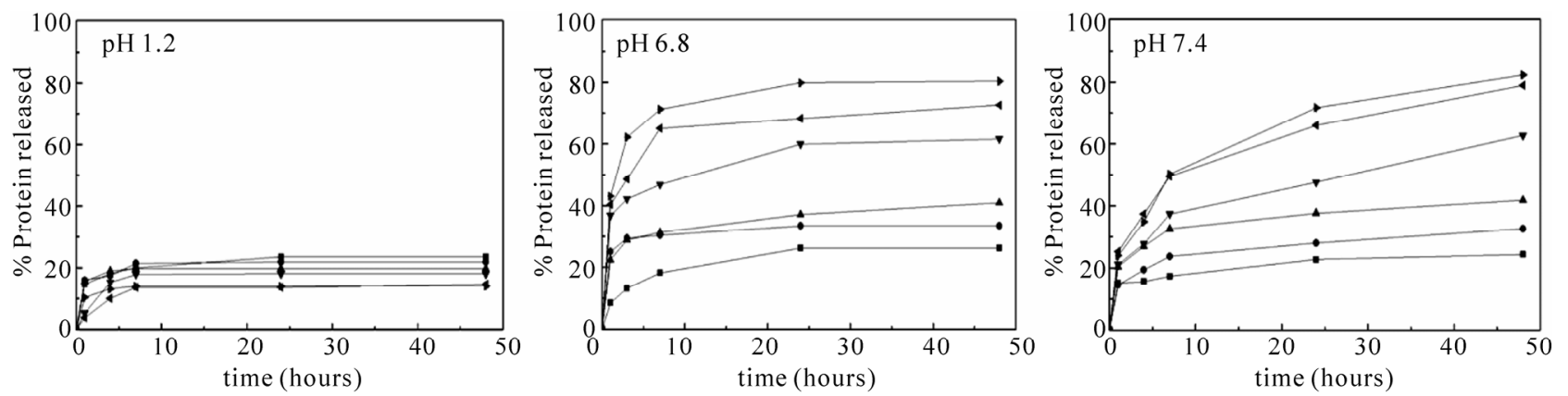

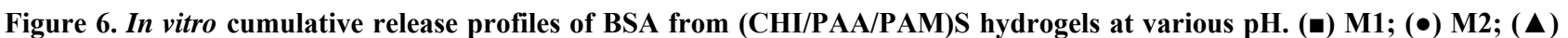
M3; ( $\mathbf{\nabla})$ M4; (४) M5; (\) M6.
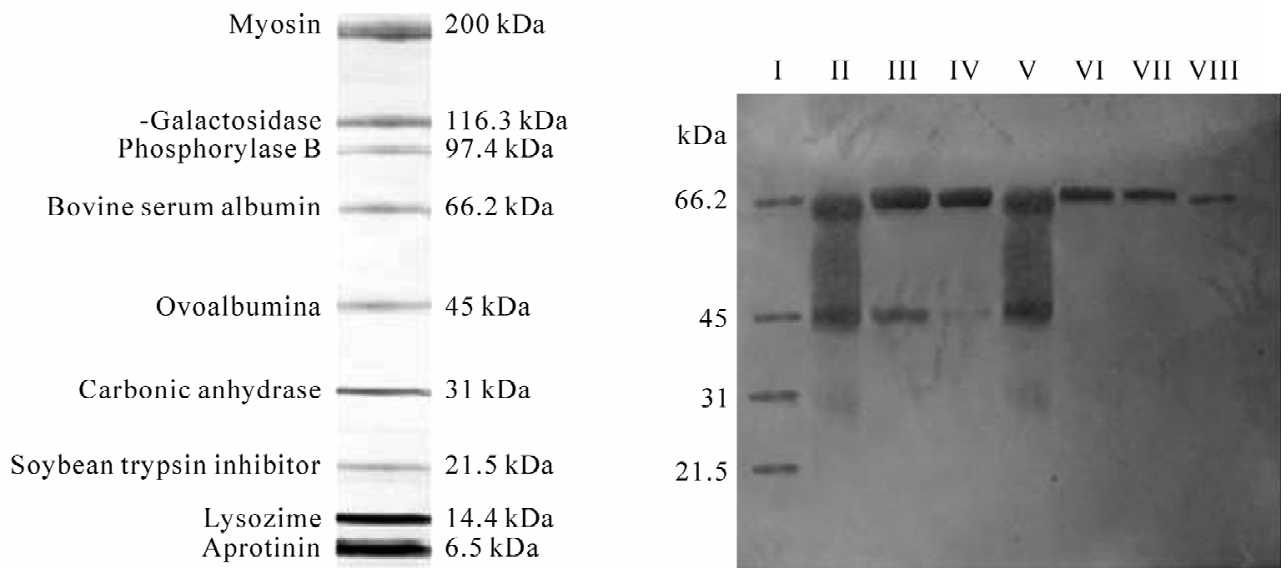

Figure 7. SDS-PAGE analysis of BSA. Lane I corresponds molecular weight markers. Lanes II, III, IV correspond BSA released from (QUI/PAA/PAM)A hydrogels at pHs 1.2, 6.8 and 7.4 respectively. Lanes V, VI, VII correspond BSA released from (QUI/PAA/PAM)S hydrogels at pHs 1.2, 6.8 and 7.4 respectively. Lane VIII correspond BSA standard.

the released protein. On the other hand, lanes IV, VI and VII indicate that BSA released from (QUI/PAA/PAM)A hydrogels at $\mathrm{pH} 7.4$ and (QUI/PAA/PAM)S hydrogels at pH 6.7 and 7.4 maintain its structural integrity, which is a premise for preserving the protein activity.

\subsection{Cytotoxicity Test}

Hidrogel cytotoxicity was assessed by determining vi- ability of cells by the MTT assay. Viability of human skin dermal fibroblast exposed to hydrogel extract is shown in Figures 8 and 9. For (QUI/PAA/PAM) hydrogels at different times. All the samples have the same behavior than the control Thermanox (TMX), resulting not cytotoxic, except for M1 and M6 (QUI/PAA/PAM)A at 7 days which presents a viability below $80 \%$ with respect to the control. 


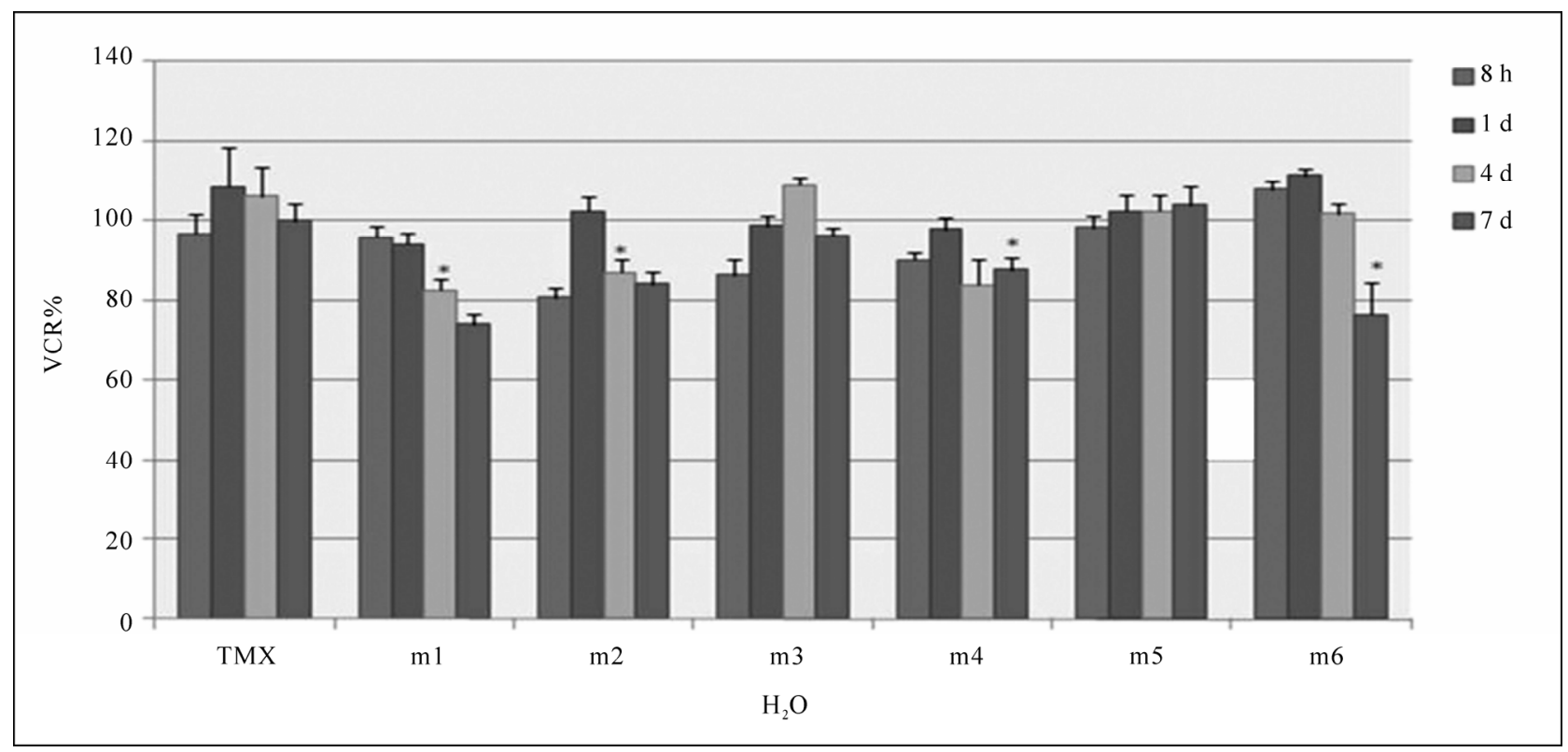

Figure 8. Results of MTT test for M1-M6 (CHI/PAA/PAM)A discs. Values are average \pm standard deviation for $n=8$. *p $<$ 0.05 and $* * * p<0.001$ with respect to TMX.

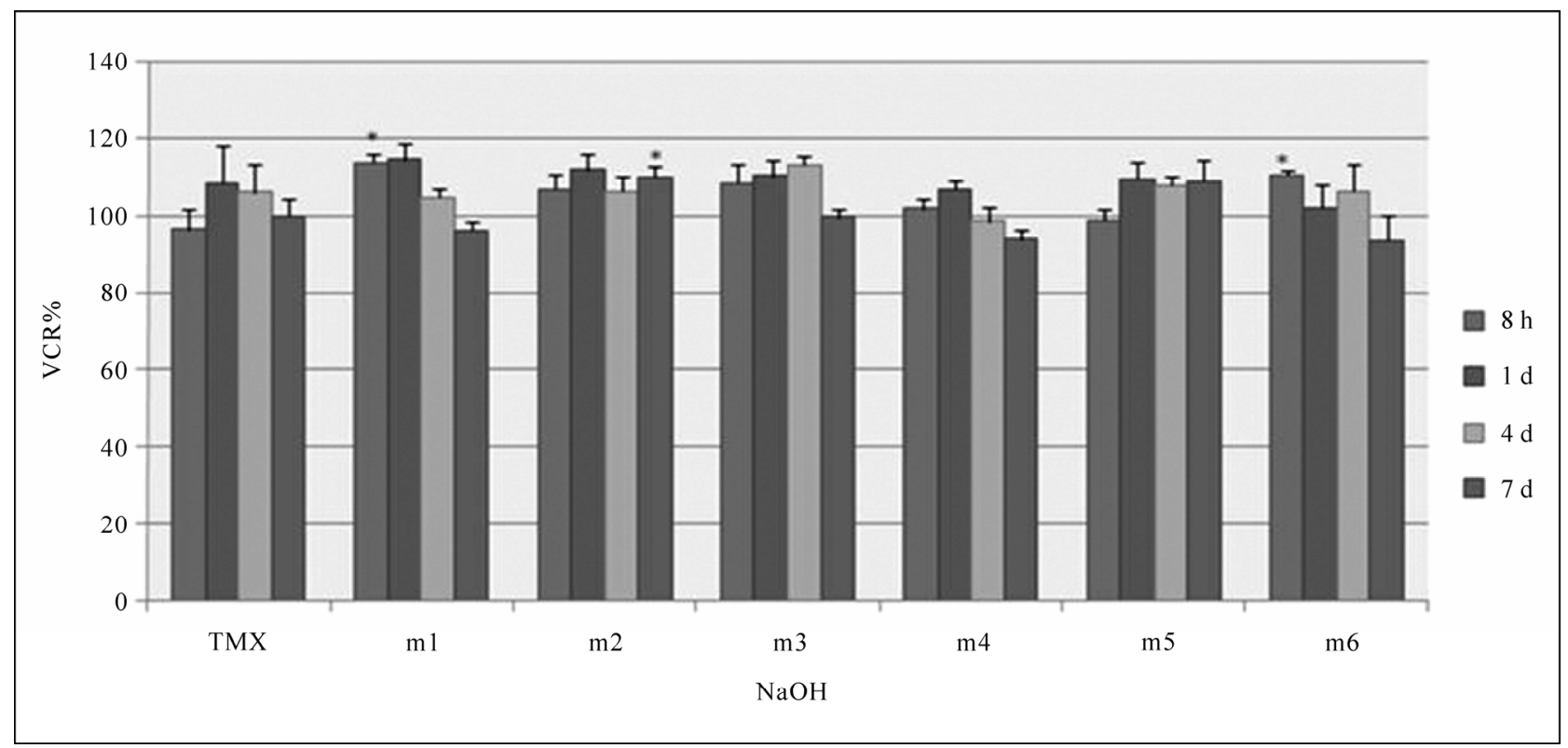

Figure 9. Results of MTT test for M1-M6 (CHI/PAA/PAM)S discs. Values are average \pm standard deviation for $n=8$. *p $<$ 0.05 and $* * * p<0.001$ with respect to TMX.

This could be related with the possible presence of residual monomer in these systems, M1 richest in AM monomer and M6 richest in AA monomer that independently of the exhaustive washings with double distilled water could have remained present.

\section{Conclusions}

Interpenetrated chitosan-poly(acrylic acid-co-acrylamide) hydrogels with different compositions were synthesized by the free radical polymerization of $\mathrm{AM}$ and $\mathrm{AA}$ in presence of the CHI and MBA. Hydrogels swelling was controlled by the interaction between the amino groups of AM and the carboxylic groups of AA. Therefore, water uptake decreased with increasing AA concentration in the polymer and was also higher at $\mathrm{pH}$ 7.4. After treatment with $0.1 \mathrm{~N} \mathrm{NaOH}$ swelling capacity increased con- 
siderably due to AM hydrolysis but decreased considerably with increasing ionic strength. Mechanical properties of these systems can be tailored by adjusting hydrogel composition i.e. for high mechanical strength hydrolysed hydrogels prepared with $0.56 \mathrm{~g} \mathrm{AA}, 0.16 \mathrm{~g}$ Am and 0.08 g CHI should be preferred. BSA loading capacity was higher in (CHI/PAA/PAM)S hydrogels due to their high water content and greater porosity.

Hydrogels were not cytotoxic for both systems except for samples M1(QUI/PAA/PAM)A and M6(QUI/PAA/ PAM)A. BSA release experiments showed that these hydrogels (hydrolysed and non hydrolysed) are capable of sustained release at $\mathrm{pH} 6.8$ and 7.4 after $10 \mathrm{~h}$. BSA released from (QUI/PAA/PAM)A and (QUI/PAA/PAM)S hydrogels maintained its structural integrity at 6.7 and 7.4, which is a desirable requirement for preserving protein activity. The fact that (CHI/PAA/PAM)S hydrogels exhibited limited BSA release in simulated gastric fluid and sustained release in simulated intestinal fluids suggests that they are good candidates as matrices for colon-specific sustained protein release formulations.

\section{Acknowledgements}

M. Bocourt thanks the financial support for fellowship program for doctoral training in the Cuba-Mexico Ministry for Foreign Affairs of Mexico. We like to thank Dr. Ileana Echevarria Machado at the Biochemistry and Molecular Biology of Plants Department for UV spectroscopy and Dr. Francis Avilés Cetina for mechanical testing at the materials Department. This project is funding from SEP-CONACYT. Project 2006-C01-61252, México.

\section{REFERENCES}

[1] A. Singh, S. S. Narvi, P. K. Dutta and N. D. Pandey, "External Stimuli Response on a Novel Chitosan Hydrogel Crosslinked with Formaldehyde," Bulletin of Materials Science, Vol. 29, No. 3, June 2006, pp. 233-238. doi:10.1007/BF02706490

[2] C. C. Lin and K. Anseth, "PEG Hydrogels for the Controlled Release of Biomolecules in Regenerative Medicine," Pharmaceutical Research, Vol. 26, No. 3, March 2009, pp. 631-643. doi:10.1007/s11095-008-9801-2

[3] J. Kopeček, "Hydrogel from Soft Contact Lenses and Implants to Self-Assembled Nanomaterials," Journal of Polymer Science Part A: Polymer Chemistry, Vol. 47, No. 22, November 2009, pp. 5929-5946. doi:10.1002/pola. 23607

[4] K. Murota, S. Sakamoto and K. Kudo, "Reversible Immobilization of Protein into Hydrogel Using Designed Coiled-Coil Peptides," Chemistry Letters, Vol. 36, No. 11, September 2007, pp. 132-137. doi:10.1246/cl.2007.1320

[5] E. Fonseca, F. Campos, A. Pereira, R. Cerqueira, L. Guilherme, W. L. Vasconcelos, Z. I. Portela and H.
Sander, "Synthesis and Characterization of Poly(Vinyl Alcohol) Hydrogels and Hybrids for rMPB70 Protein Adsorption," Journal of Materials Research, Vol. 9, No. 2, June 2006, pp. 185-190. doi:10.1590/S1516-14392006000200014

[6] P. M. Torre, Y. Enobakhare, G. Torrado and S. Torrados, "Release of Amoxicillin From Polyionic Complexs of Chitosan and Poly(Acrylic Acid), Study of Polymer/Polymer and Polymer/Drug Interactions within the Network Structure," Biomaterials, Vol. 24, No. 8, April 2003, pp. 1499-1509. doi:10.1016/S0142-9612(02)00512-4

[7] L. I. Yang, J. S. Chu and J. A. Fix, "Colon-Specific Drug Delivery: New Approaches and in Vitro/in Vivo Evaluation," International Journal of Pharmaceutics, Vol. 235, No. 1, March 2000, pp. 1-15. doi:10.1016/S0378-5173(02)00004-2

[8] Y. Qui and K. Park, "Environment-Sensitive Hydrogels for Drug Delivery," Advanced Drug Delivery Reviews, Vol. 53, No. 3, December 2001, pp. 321-339. doi:10.1016/S0169-409X(01)00203-4

[9] S. Torrado, P. Prada, M. Paloma and S. Torrado, "Chitosan-Poly(Acrylic) Acid Polyionic Complex: In Vivo Study to Demostrate Prolonged Gastric Retention," Biomaterials, Vol. 25, No. 5, July 2003, pp. 917-923. doi:10.1016/S0142-9612(03)00579-9

[10] S. Jeong, S. Jun and S. I. Kim, "Swelling Behavior of Interpenetrating Polymer Network Hydrogels Composed of Poly(Vinyl Alcohol) and Chitosan," Reactive and Functional Polymers, Vol. 55, No. 1, February 2003, pp. 5359. doi:10.1016/S1381-5148(02)00214-6

[11] A. Borzacchielo, L. Ambrosio, P. A. Netti, L. Nicolais, C. Peniche, A. Gallardo and J. S. Román, "Chitosan-Based Hydrogels: Synthesis and Characterization," Journal of Materials Science: Materials in Medicine, Vol. 12, No. 10, May 2001, pp. 861-864. doi:10.1023/A:1012851402759

[12] T. R. Singh, G. Indu, S. Reena and A. K. Nagpal, "Synthesis of Poly(Acrylamide-co-Acrylic Acid) Based Superabsorbent Hydrogels: Study of Network Parameters and Swelling Behaviour," Polymer-Plastics Technology and Engineering, Vol. 46, No. 5, May 2007, pp. 481-488. doi:10.1080/03602550701297095

[13] A. Gemeinhart, A. Richard, et al., "pH-Sensitivity of Fast Responsive Superporous Hydrogels," Journal of Biomaterials Science, Polymer Edition, Vol. 11, No. 12, December 2000, pp. 1371-1380. doi:10.1163/156856200744390

[14] Y. Shen, X. Zhang, J. Lu, A. Zhang, K. Chen and A. Li, "Effect of Chemical Composition on Properties of $\mathrm{pH}$ -Responsive Poly(Acrylamide-co-Acrylic Acid) Microgels Prepared by Inverse Microemulsion Polymerization," Colloids and Surfaces A: Physicochemical and Engineering Aspects, Vol. 350, No. 1, October 2009, pp. 87-90.

doi:10.1016/j.colsurfa.2009.09.009

[15] S. Duran, D. Olpan and O. Güven, "Synthesis and Characterization of Acrylamide-Acrylic Acid Hydrogels and 
Adsorption of Some Textile Dyes," Nuclear Instruments and Methods in Physics Research Section B, Vol. 151, No. 1, May 1999, pp. 196-199. doi:10.1016/S0168-583X(99)00151-2

[16] A. Li and A. Wang, "Synthesis and Properties of Clay-Based Superabsorbent Composite," European Polymer Journal, Vol. 41, No. 7, May 2005, pp. 1630-1637. doi:10.1016/j.eurpolymj.2005.01.028

[17] A. Fiumefreddo and M. Utz, "Bulk Streaming Potential in Poly(Acrylic Acid)/Poly(Acrylamide) Hydrogels," Macromolecules, Vol. 43, No. 13, January 2010, pp. 58145819. doi: $10.1021 / \mathrm{ma1} 00565 \mathrm{~s}$

[18] M. V. Risbud and R. R. Bhonde, "Polyacrylamide-Chitosan Hydrogel: In Vitro Biocompatibility and Sustained Antibiotic Release Studies," Drug Delivery, Vol. 7, No. 2, January 2000, pp. 69-75. doi:10.1080/107175400266623

[19] C. Peniche, W. Arguelles-Monal, N. Davidenko, R. Sastre, A. Gallardo and J. S. Roman, "Self-Curing Membranes of Chitosan/PAA IPNs Obtained by Radical Polymerization: Preparation, Characterization and Interpolymer Complexation," Biomaterials, Vol. 20, No. 20, October 1999, pp. 1869-1878. doi:10.1016/S0142-9612(99)00048-4

[20] M. Recillas, L. L. Silva, C. Peniche, F. M. Goycoolea, M. Rinaudo and W. M. Argüelles-Monal, "Thermo-Responsive Behavior of Chitosan-g-Nisopropylacrylamide Copolymer Solutions," Biomacromolecules, Vol. 10, No. 6, April 2009, pp. 1633-1641. doi:10.1021/bm9002317

[21] A. Srivastava, D. K. Mishra and K. Behari, "Graft Copolymerization of N-Vinyl-2-Pyrrolidone onto Chitosan: Synthesis, Characterization and Study of Physicochemical Properties," Carbohydrate Polymers, Vol. 80, No. 3, May 2010, pp. 790-798. doi:10.1016/i.carbpol.2009.12.031

[22] F. Long, Y. Chiun, H. Fa and H. Wen, "In Vivo Biocompatibility and Degradability of a Novel Injectable Chitosan-Bead Implant," Biomaterials, Vol. 23, No. 1, January 2002, pp. 181-191. doi:10.1016/S0142-9612(01)00094-1

[23] M. Rinaudo, "Chitin and Chitosan: Chemistry, Properties and Applications," Progress in Polymer Science, Vol. 31, No. 7, January 2006, pp. 603-632. doi:10.1016/j.progpolymsci.2006.06.001

[24] G. R. Mahdavinia, A. Pourjavadi, H. Hosseinzadeh and M. J. Zohuriaan, "Modified Chitosan 4. Superabsorbent Hydrogels from Poly(Acrylic Acid-Co-Acrylamide) Grafted Chitosan with Salt- and pH- Responsiveness Properties," European Polymer Journal, Vol. 40, No. 7, July 2004, pp. 1399-1407. doi:10.1016/j.eurpolymj.2004.01.039

[25] DC Protein Assay, "Bio-Rad Protein Assay Kit Manual,"
Bio-Rad Laboratories, Hercules, 1998.

[26] U. K. Laemmli, "Cleavage of Structural Proteins during the Assembly of the Head of Bacteriophage T4," Nature, Vol. 227, No. 5259, August 1970, pp. 680-685.

[27] H. Wan, R. L. Williams, P. J. Doherty and D. F. Williams, "The Cytotoxicity Evaluation of Kevlar and Silicon Carbide by MTT Assay," Journal of Materials Science: Materials in Medicine, Vol. 5, No. 6, December 1994, pp. 441-445. doi:10.1007/BF00058980

[28] X. Z. Zhang, D. Q. Wu and C. Chu, "Synthesis, Characterization and Controlled Drug Release of Thermosensitive IPN-PNIPAM Hydrogels," Biomaterials, Vol. 25, No. 17, August 2004, pp. 3793-3805. doi:10.1016/j.biomaterials.2003.10.065

[29] W. Argüelles-Monal and C. Peniche-Covas, "Study of the Interpolyelectrolyte Reaction between Chitosan and Carboxymethyl Cellulose," Die Makromolekulare Chemie, Rapid Communications, Vol. 9, No. 10, June 1988, pp. 693-697. doi:10.1002/marc.1988.030091004

[30] M. Bocourt, N. Bada, W. Argüelles-Monal and C. Peniche, "Síntesis y Caracterización de Redes Poliméricas Interpenetradas de Quitosana-Poli(Ácido Acrílico-co-Acrilamida)," Revista CENIC Ciencias Químicas, Vol. 40, No. 2, February 2009, pp. 81-88.

[31] H. Schott, "Swelling Kinetics of Polymers," Journal of Macromolecular Science, Vol. 31, No. 1, March 1992, pp. 1-9. doi:10.1080/00222349208215453

[32] K. Sivadasan, P. Somasundaran and N. J. Turro, "Fluorescence and Viscometry Study of Complexation of Poly (Acrylic Acid) with Poly(Acrylamide) and Hydrolysed Poly(Acrylamide)," Colloid \& Polymer Science, Vol. 269, No. 2, April 1991, pp. 131-113. doi:10.1007/BF00660302

[33] C. L. Bell and N. A. Peppas, "Biomedical Membranes from Hydrogels and Interpolymer Complexes," In: N. A. Peppas and R. S. Langer, Eds., Advances in Polymer Science 122, Biopolymer II, Springer-Verlag, Berlin, 1995, pp. 125-175.

[34] Q. Tang, S. X, Q. Li, J. Wu and J. Lin, “A Simple Route to Interpenetrating Network Hydrogel with High Mechanical Strength," Journal of Colloid Science, Vol. 339, No. 1, July 2009, pp. 45-52.

[35] W. Gombotz and A. S. Hoffman, "Medicine and Pharmacy," In: N. A. Peppas, Ed., Hydrogels in Medicine and Pharmacy, CRC Press, Boca Raton, 1986, pp. 95-126.

[36] E. Karadag, D. Saraydin, H. Nursevin and O. Guven, "Adsorption of Bovine Serum Albumin to AcrylamideItaconic Acid Hydrogels," Polymers for Advanced Technologies, Vol. 5, No. 10, April 1994, pp. 664-668. 